\title{
FRUTING PHENOLOGY OF EIGHT Shorea SPECIES IN SINHARAJA MAN AND BIOSPHERE RESERVE
}

\section{B K H C Munidasa, C V S Gunatilleke and I A U N Gunatilleke Department of Botany, University of Peradeniya}

The canopy of Sinharaja rain forest is dominated by Mesua and Shorea spp., which are endemic to Sri Lanka. Information on the fruiting phenology of Shorea is vital, in terms of identifying trees as mother trees and collecting seeds for restoration and reforestation of degraded forest areas in the south-western part of Sri Lanka.

The phenology of eight Shorea species, [S. affinis, S. congestiflora, S. trapezifolia and $S$. zeylanica belonging to the Thiniya group and $S$. cordifolia, $S$. megistophylla, $S$. worthingtonii and $S$. disticha belonging to the Beraliya group] were examined for eighteen years. Fruiting of selected individuals was recorded fort-nightly as a percentage of the observable part of the crown in flower. The effect of environmental parameters on fruiting was assessed using Spearman rank correlation coefficient.

In all species, the number of trees participating in a given fruiting event differed greatly between years. Individuals of $S$. trapezifolia and $S$. zeylanica had more intense fruiting activity $(>50 \%)$ in most years while, it was only $1-50 \%$ in $S$. congestiflora. Fruiting intensities of individuals of the Beraliya group varied relatively little among different fruiting episodes. An annual fruiting pattern among the Thiniyas and a supra-annual pattern in the Beraliyas were observed. The number of flowering episodes per tree was high in members of the Thiniya group. Fruit fall was tightly synchronized among the Beraliyas, but sequential among the Thiniyas.

The monthly rainfall and the fruiting intensities of all Shorea species, except in $S$. cordifolia and $S$. zeylanica, were significant. The seasonal rainfall and fruiting intensities of four Shorea species were significantly correlated. The timing and intensity of fruiting was observed to coincide with favorable environmental conditions.

This project was funded by grants from by the USAID (Grant No: DPE-5542-G-554073-00) through Harvard University, U. S. A. and the John D. and Catherine T. MacArthur Foundation and the Britin Scholarship Fund

Proceedings of the Ninth Annual Forestry and Environment Symposium 2003 of the Department of Forestry and Environmental Science, University of Sri Jayewardenepura, Sri Lanka 